\title{
Uma Perspectiva Crítica do Novo Regime Fiscal para a Dinâmica de Curto e Longo Prazo da Economia brasileira
}

\author{
Hugo Carcanholo lasco Pereira \\ Doutorando em Economia do CEDEPLAR/UFMG \\ E-mail: hclpereira@cedeplar.ufmg.br; \\ Tarik Tanure \\ Doutorando em Economia do CEDEPLAR/UFMG \\ E-mail: tmptanure@cedeplar.ufmg.br; \\ André Teixeira \\ Doutorando em Economia do CEDEPLAR/UFMG \\ E-mail: andreteixeira.eco@hotmail.com \\ Fabrício J. Missio \\ Professor do Departamento de Economia - CEDEPLAR/UFMG \\ E-mail: fjmissio@cedeplar.ufmg.br
}

Resumo: O artigo propõe uma perspectiva crítica do novo regime fiscal para a dinâmica de curto e longo prazo da economia brasileira. Para tanto, o trabalho inicialmente analisa a situação dos principais agregados macroeconômicos da economia brasileira no triênio 2014-2016, destacando a recessão e o problema fiscal. Em seguida, analisam-se criticamente dois elementos: o primeiro, mais associado ao longo prazo, refere-se a distribuição de recursos no orçamento e os impactos nos gastos em capital humano (educação e saúde) e, o segundo (curto prazo), refere-se à possibilidade de o Novo Regime Fiscal aumentar o grau de inercialização da economia brasileira e, com isso, prejudicar o crescimento econômico. Por fim, apresenta-se uma perspectiva crítica do "modelo" econômico presente no diagnóstico que embasou o novo regime fiscal. A conclusão é de que as soluções propostas para resolver a crise fiscal e econômica são questionáveis e configuram uma aposta altamente arriscada.

Palavras-Chave: Recessão, austeridade, ideologia econômica.

Abstract: The objective of this paper is to present a critical perspective for the "there is no alternative" ideology present in the New Fiscal Regime for the short and long term dynamics of the Brazilian economy. For this, the paper initially analyzes the situation of the main macroeconomic aggregates of the Brazilian economy in the triennium 20142016, highlighting the recession and the fiscal problem. Then, two elements are critically analyzed: $i$ - the long-term: the distribution of the budget resources and the impacts on human capital (education and health) and ii- the short-term: the possibility that the PEC 55 reinforces the indexation of Brazilian economy and therefore reduces the economic growth. Finally, a critical perspective of the economic "model" present in the diagnosis that underlies the New Fiscal Regime is presented. The conclusion is that the solutions proposed to solve the fiscal and economic crisis are questionable and constitute a highly risky bet.

Key Words: Recession, austerity and ideology. 


\section{INTRODUÇÃO}

A economia brasileira no triênio 2014-2016 passou por uma dinâmica recessiva em termos de produto, emprego e renda, em consonância com um processo inflacionário. Neste período, houve a intensificação da crise político-institucional, especialmente após o processo de impeachment da presidente Dilma Roussef. Ao mesmo tempo, estabeleceu-se uma ampla discussão sobre o problema fiscal brasileiro. O setor público brasileiro encontra-se imerso em uma grave crise fiscal, com um déficit primário esperado de aproximadamente 170 bilhões para 2016 e de 140 bilhões em 2017. Se, por um lado, o reconhecimento do problema fiscal atual é amplamente compartilhado pelos analistas, por outro, não existe um consenso acerca das suas origens e nem de quais são as políticas mais adequadas para resolver esse problema. À grosso modo, identificam-se três grupos:

a) Aqueles que enfatizam o problema do crescimento rígido de caráter não cíclico das despesas primárias;

b) Os que explicam o problema fiscal pela ótica da queda cíclica da arrecadação tributária;

c) Os economistas que tentam agregar essas duas perspectivas, defendendo a contenção das despesas e mudanças em diferentes aspectos da política econômica (como a redução dos juros e/ou o aperfeiçoamento da arrecadação tributária, por exemplo).

As diferenças analíticas são de suma importância porque estabelecem as características da estratégia de combate ao problema em questão.

Sob a orientação do primeiro grupo, o governo de Michel Temer propôs e aprovou uma ementa constitucional provisória (PEC 241/55 ou Novo Regime Fiscal) para congelar o orçamento primário em termos reais pelos próximos dez anos. O objetivo, segundo essa proposta, é reverter a trajetória crescente dos gastos primários para estabilizar a razão entre dívida pública e PIB. Assim, no curto prazo a medida implicaria em menor necessidade de financiamento público e maior geração de superávit primário, o que permitiria estabilizar o crescimento da dívida. Posteriormente, tal medida engendraria um processo de crescimento econômico através da redução estrutural da SELIC e, consequentemente, de estímulo ao investimento. A PEC 241/55 baseia-se no diagnóstico empírico de que a despesa real cresceu 51\% acima da inflação entre 2008 e 2015 ao passo que as receitas variaram 14,5\%. A ideia seria reverter a tendência de crescimento real do gasto público, garantindo o superávit primário para o pagamento da dívida pública.

Todavia, existe uma série de questionamentos em relação a essa proposta. Uma parcela significativa dos analistas acredita que o diagnóstico sobre os problemas econômicos e fiscais presentes nela é equivocado. Para estes, existem diferentes formas de resolver o problema fiscal sem necessariamente comprometer o bem-estar das camadas mais vulneráveis da população. Por exemplo, o ajuste poderia ser feito mediante uma reforma tributária, que reduzisse a tributação do lucro e da produção das empresas, ao mesmo tempo em que se concentraria o ajuste fiscal de curto prazo sobre uma pequena parcela da poupança dos mais ricos, não diretamente relacionada ao 
p. 53 - Uma perspectiva crítica do novo regime fiscal para a dinâmica de curto e longo prazo da economia brasileira

investimento. Isso promoveria um maior nível de emprego e produto, enquanto se aprimora e se debate com a sociedade outras propostas de reformas estruturais das despesas (Documento Austeridade e Retrocesso, 2016).

O objetivo deste trabalho é apresentar uma perspectiva crítica à ideologia do "não há alternativa" presente no Novo Regime Fiscal Brasileiro, investigando as possíveis consequências da aprovação da PEC55/241 para o curto e longo prazo da economia brasileira. Inicialmente propõe-se uma análise de dois dos principais argumentos que fundamentaram a aprovação do Novo Regime Fiscal, o de que haverá melhoras na distribuição de recursos no orçamento e o de que a política fiscal tornar-se-á anticíclica e promoverá a retomada do crescimento.

No primeiro caso, demonstra-se que os graus de liberdade para as realocações são mínimos e que o "teto dos gastos" na verdade pode acabar reduzindo a oferta de serviços públicos à população e inviabilizando a retomado do crescimento por meio de investimentos públicos, e que, ademais, tal medida reduz o investimento em educação e inovação tecnológica, o que reafirma a condição de subdesenvolvimento da economia brasileira. No segundo caso, demonstra-se que a introdução de rigidez (inércia) na economia pode piorar a situação fiscal do Governo dado a exigência de taxas juros maiores para controlar a inflação, e a relação do Novo Regime Fiscal com o crescimento econômico. Por fim, apresenta-se uma perspectiva crítica do "modelo" econômico presente no diagnóstico que embasou o novo regime fiscal.

O artigo encontra-se dividido em três seções, além desta introdução e das considerações finais. Na seção 2 realiza-se um breve levantamento acerca da dinâmica da economia brasileira e das finanças públicas com vistas a entender o quadro econômico e fiscal; a seção seguinte analisa a distribuição de recursos no orçamento e o impacto disto na situação de longo prazo da economia brasileira. Na seção 4 analisa-se a consistência da PEC 241/55 dentro do diagnóstico de Meirelles referente ao argumento de que a política fiscal tornar-se-á anticíclica e que promoverá o crescimento econômico.

\section{A EVOLUÇÃO DA ECONOMIA BRASILEIRA ENTRE 2014 E 2016}

O triênio 2014-2016 da economia brasileira é notoriamente marcado por um quadro recessivo. Isso fica evidente quando se observa que o produto trimestral dos três grandes setores da economia (agropecuária, indústria e serviços) sofreram forte decréscimo a partir do primeiro trimestre de 2014, de $-24 \%,-18 \%$ e $-19 \%$ respectivamente (Gráfico 1) (IBGE, 2016). 
Gráfico 1- Evolução Trimestral Dessazonalizada dos Componentes do PIB entre 2010 e $2016(1995=100)$

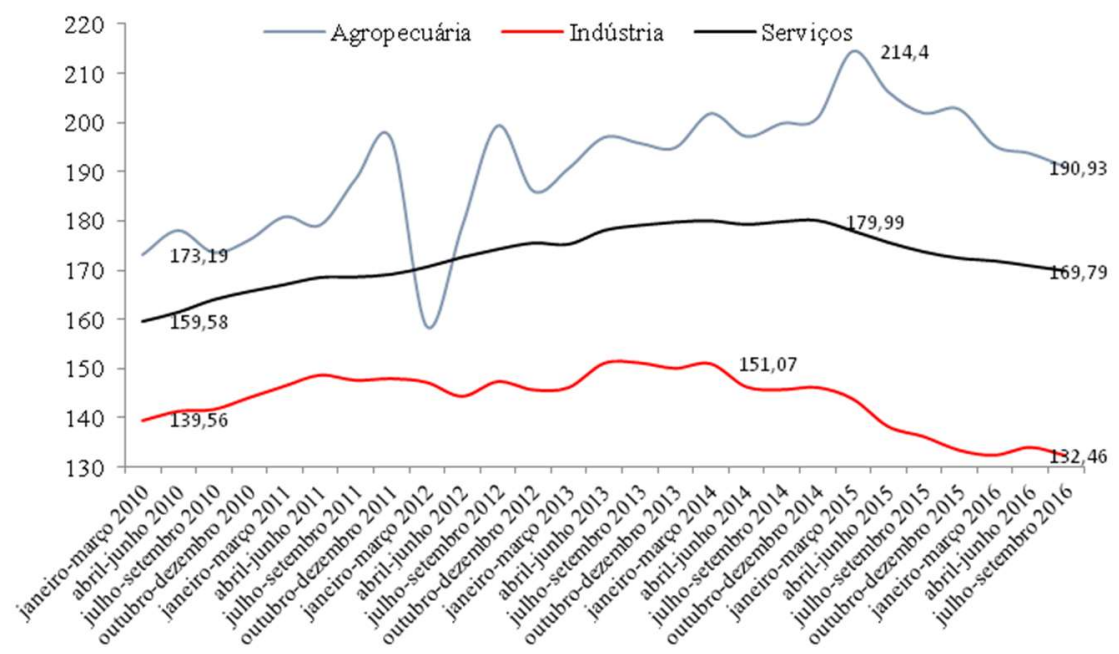

Fonte: Elaboração dos autores com base nos dados fornecidos pelo IBGE (sidra.ibge.gov.br/home/scnt)

A conjuntura recessiva se deve à queda da demanda agregada e à crise expectacional da economia brasileira, somado aos efeitos da crise e da conjuntura internacional ${ }^{1}$. Ademais, uma concentração não usual de choques atingiu o país nesse período, comprometendo seu crescimento (Pires, 2016). Os principais componentes da demanda mostram claros sinais de arrefecimento no período (Gráfico 2). Outros fatores estruturais podem ter ampliado os efeitos iniciais da queda da demanda, como a baixa produtividade do trabalho, a baixa intensidade de capital per capita (especialmente em alguns setores) ou ainda a presença de gargalos em logística, transportes, infraestrutura, etc.

Gráfico 2 - Evolução trimestral dessazonalizada da demanda agregada entre 2010 e $2016(1995=100)$

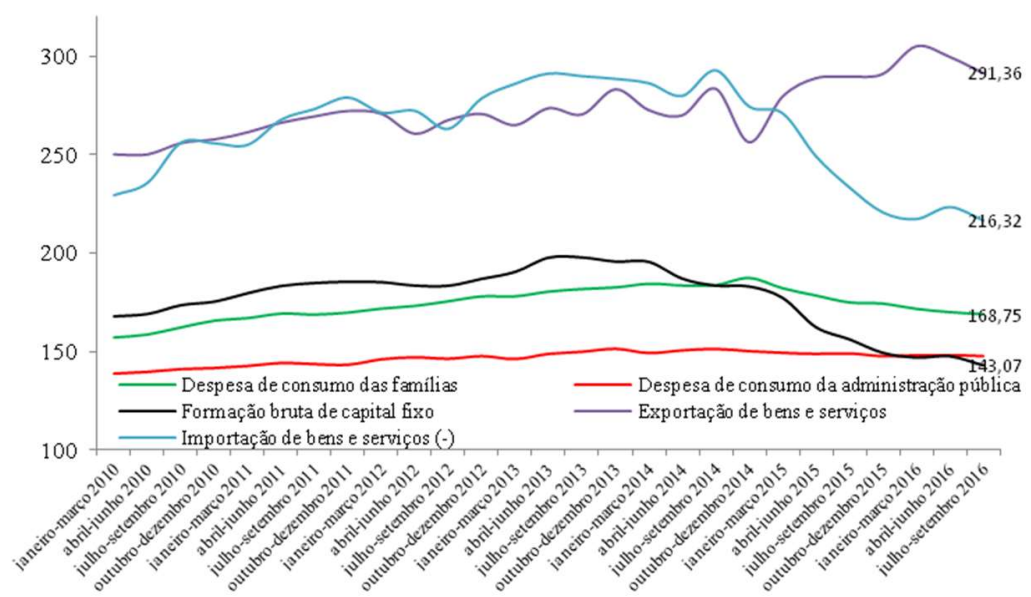

Fonte: Elaboração dos autores com base nos dados fornecidos pelo IBGE (sidra.ibge.gov.br/home/scnt)

\footnotetext{
${ }^{1}$ Para diferentes ênfases interpretativas sobre a crise no período ver Rossi e Mello (2016).
} 
p. 55 - Uma perspectiva crítica do novo regime fiscal para a dinâmica de curto e longo prazo da economia brasileira

Em relação a cada um dos componentes da demanda, destaca-se que:

a) Formação bruta de capital fixo²: A partir da eleição de Dilma Roussef em 2014 a economia brasileira passou por uma intensificação da crise política, que culminou no impeachment da presidente então eleita democraticamente, na cassação e posterior prisão do ex-presidente da Câmara dos Deputados Eduardo Cunha e em uma série de denúncias contra notórios políticos brasileiros, tendo como agravante os desdobramentos da operação Lava Jato. Neste período o risco país elevou-se sistematicamente, passando de um patamar pós-eleições de 239 pontos para 548 pontos com a confirmação do processo de impeachment (variação de 129\%). Os dados das pesquisas CNI-IBOPE referentes aos índices de desaprovação, desconfiança e avaliação do governo aumentaram consideravelmente, ilustrando a situação de insatisfação popular e instabilidade social do período. Tal situação criou instabilidade institucional e incerteza, o que se refletiu na confiança e nas expectativas de curto e longo prazo dos agentes econômicos. Em relação ao investimento, houve um forte declínio, sobretudo a partir do segundo trimestre de 2015. Tamanho declínio pode ser relacionado ao aumento da capacidade ociosa das indústrias e do endividamento das empresas. O índice de utilização da capacidade instalada industrial indica uma elevação do grau de ociosidade do setor industrial a partir de Setembro de 2014, passando de $81 \%$ nesta data para $77,2 \%$ em Julho de 2016 (Gráfico 3). Outro fator importante neste processo é o envolvimento de empreiteiras e da Petrobrás nos escândalos políticos e as consequentes paralisações de seus investimentos, que correspondem a grande parte da formação bruta de capital fixo da economia brasileira.

Gráfico 3- Utilização da capacidade instalada e taxa de desemprego aberta

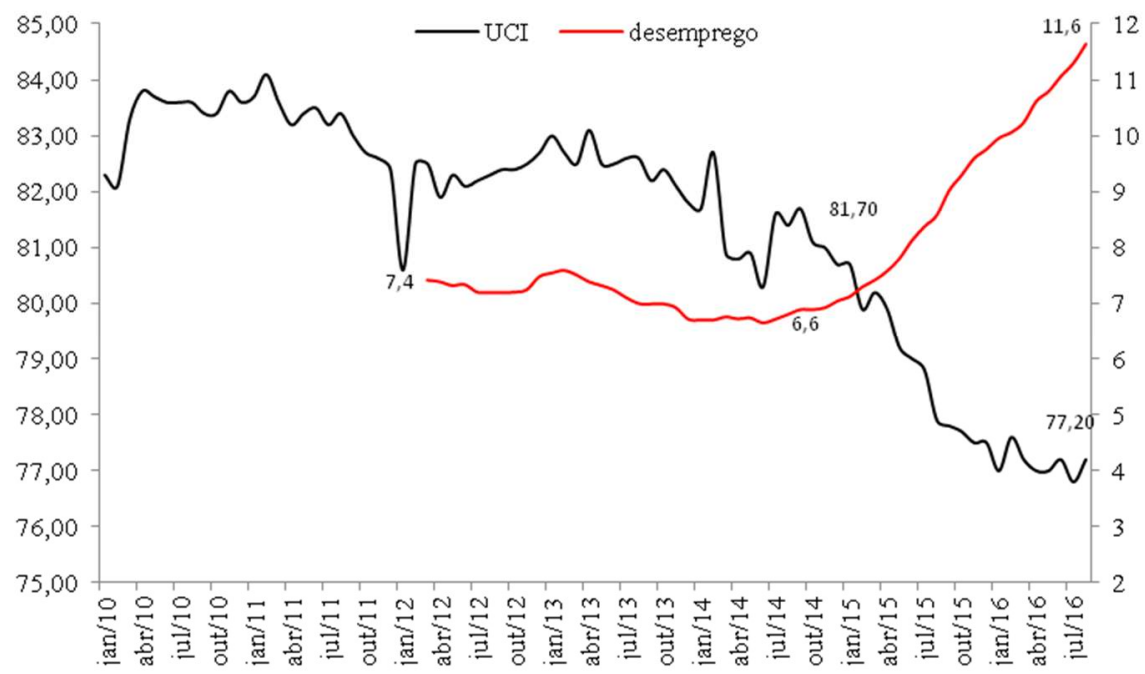

Fonte: Elaboração dos autores com base nos dados fornecidos pela CNI

(www.portaldaindustria.com.br/estatisticas/) e pelo Banco Central do Brasil (www.bcb.gov.br/pt$\mathrm{br} / \# ! /$ home)

\footnotetext{
${ }^{2}$ Representa o quanto as empresas aumentaram os seus bens de capital, ou seja, aqueles bens que servem para produzir outros bens. São basicamente máquinas, equipamentos e material de construção. Esse indicador (utilizado aqui como proxy para o investimento) é importante porque indica se a capacidade de produção do país está crescendo e também se os empresários estão confiantes no futuro.
} 
b) Consumo das famílias: A queda do consumo das famílias a partir do primeiro trimestre de 2015 pode ser explicada por vários fatores, dentre os quais se destacam: i) o processo inflacionário da economia brasileira a partir de 2015 que reduziu o poder de compra do salário real; ii) a elevação da taxa de juros para consumo por conta do aumento da SELIC (Gráfico 3) e do risco bancário (aumento na inadimplência desde 2015); iii) uma expressiva taxa de desemprego, que chegou a 12,6\% em Julho de 2016 , ante os 6,6\% em Junho de 2014; iv) o esgotamento da estratégia de crescimento baseada no consumo de bens duráveis; e, v) o aumento da incerteza refletindo na preferência pela liquidez dos consumidores e dos bancos. A confirmação da queda do consumo das famílias também é corroborada pelos dados referentes ao endividamento dos consumidores da Confederação Nacional do Comércio de Bens, Serviços e Turismo (CNC), segundo a qual o número de famílias endividadas está caindo desde 2015, o que indica queda do consumo através de financiamento bancário. Observa-se, também, a elevação da inadimplência acima de 90 dias.

c) Exportação e Consumo do governo: As exportações atenuaram o quadro recessivo consideravelmente entre o último triênio de 2014 e o primeiro de 2016. Em grande parte, esse aumento se deve à recente desvalorização cambial. No entanto, com a reversão da tendência de desvalorização cambial a partir do último trimestre de 2015, o curto ciclo de aumento das exportações findou (Gráfico 4). Não obstante, frente à redução drástica das importações, a balança comercial acumulou resultados positivos. 0 volume de importações reduziu 67\% entre o terceiro trimestre de 2014 e o segundo de 2016. Por fim, neste período o consumo do governo em bens e serviços do funcionalismo público se manteve relativamente constante.

Gráfico 4- Evolução Mensal: SELIC, Câmbio e IPCA, 2010-2016

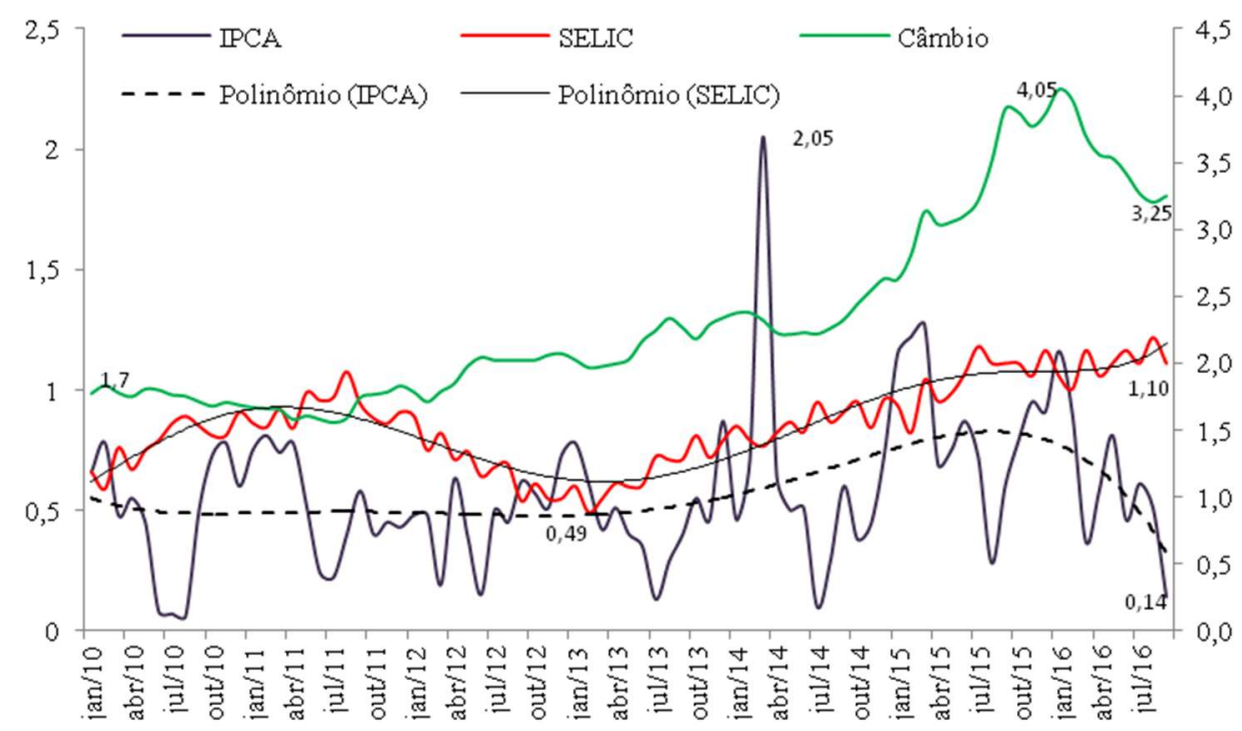

Fonte: Elaboração dos autores com base nos dados fornecidos por: Banco Central do Brasil (www.bcb.gov.br/pt-br/\#!/home IPCA) e IBGE (sidra.ibge.gov.br/home/)

Em outras palavras, a economia brasileira caracterizou-se por uma situação que se aproxima da estagflação. O descongelamento no início de 2015 dos preços públicos administrados pelo governo Dilma II e a desvalorização cambial representaram importantes pressões inflacionárias. A taxa de inflação acumulada em 2014 foi de 6,14\%, 
p. 57 - Uma perspectiva crítica do novo regime fiscal para a dinâmica de curto e longo prazo da economia brasileira

bastante próxima do teto da meta de inflação de 6,5\%. Nesse contexto, o Banco Central optou por uma política monetária restritiva para controlar o processo inflacionário via elevação da SELIC. O que gerou desincentivos aos investimentos, acentuando o quadro recessivo e contribuindo para o encarecimento da rolagem da dívida pública. Em última instância, isso exigiu maior superávit primário para o pagamento dos juros da dívida.

Por fim, ressalta-se a deterioração do quadro fiscal brasileiro. A análise da evolução mensal das contas públicas mostra que o superávit primário tornou-se negativo a partir de Novembro de 2014 (Gráfico 5). Dois fatores explicam esse resultado: o principal relaciona-se ao fato de que houve uma queda cíclica da receita líquida devido à recessão, o que levou a redução da arrecadação fiscal; por outro lado, as despesas continuaram crescendo, o que combinado com a redução da arrecadação gerou o desequilíbrio nas contas públicas (déficit). Evidentemente, a crise política e institucional tem agravado o quadro econômico afetando, por exemplo, negativamente as expectativas empresariais de curto e longo prazo, o que impede uma retomada do crescimento e da arrecadação.

Gráfico 5- Despesa Total, Receita Líquida e Resultado Primário do governo federal Acumulado nos últimos 12 meses entre 1997 e 2016

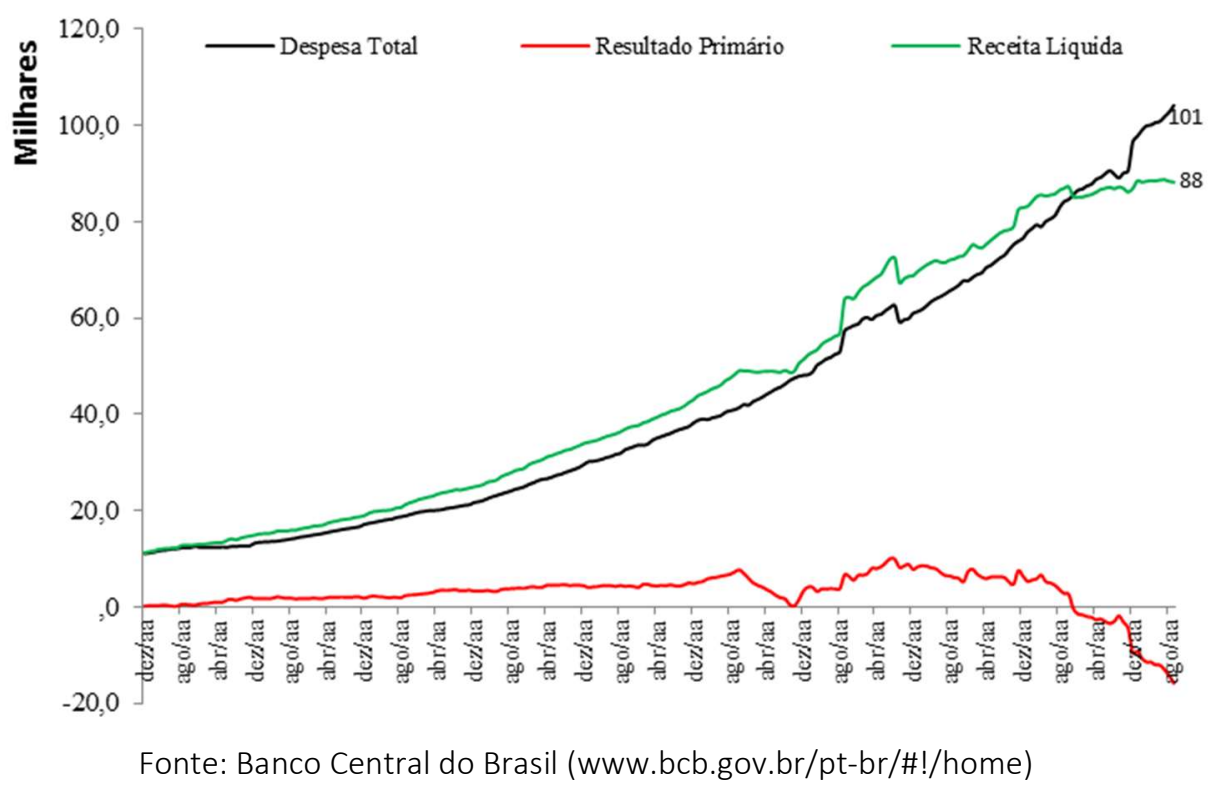

Neste contexto de desequilíbrio das contas públicas, o governo de Michel Temer propôs um Novo Regime Fiscal através de uma emenda de proposta institucional transitória, a PEC 241/55. A proposta consistiu em limitar as despesas orçamentárias e a seguridade social à variação do nível de preços do ano anterior captado pelo IPCA. Segundo o diagnóstico da equipe econômica que elaborou a PEC 241/55, o desarranjo fiscal gera elevados prêmios de risco e leva à perda de confiança dos agentes econômicos e a altas taxas de juros. Neste cenário, os investimentos se deprimem, comprometendo a capacidade de crescimento e geração de emprego e renda. O ponto a ser destacado é que há uma grande controvérsia acerca dos limites e possibilidades desse novo regime fiscal. Diversos argumentos tanto favoráveis quanto críticos foram apresentados no debate promovido durante a tramitação da proposta. A seguir, analisam-se os possíveis 
impactos tanto a longo quanto curto prazo. O objetivo é discutir até que ponto esses argumentos são sustentáveis.

\section{NO LONGO PRAZO: A PEC COMO REAFIRMAÇÃO DO SUBDESENVOLVIMENTO}

\subsection{A Distribuição de Recursos no Orçamento}

Uma das discussões em torno da PEC 241/55 é acerca de como os dispêndios na esfera federal serão distribuídos a partir do teto instituído para os gastos públicos Meirelles, no encaminhamento da PEC 241/55 (EMI 00083/2016), sugere que, a partir de tal teto, a sociedade poderia demandar realocações de recursos para as áreas que ela julgar mais importantes ${ }^{3}$. O Gráfico 6 mostra a distribuição das despesas primárias do governo central no período 2000 e 2015.

\section{Gráfico 6 - Distribuição Percentual das Despesas Orçamentárias entre 2000 e 2015}

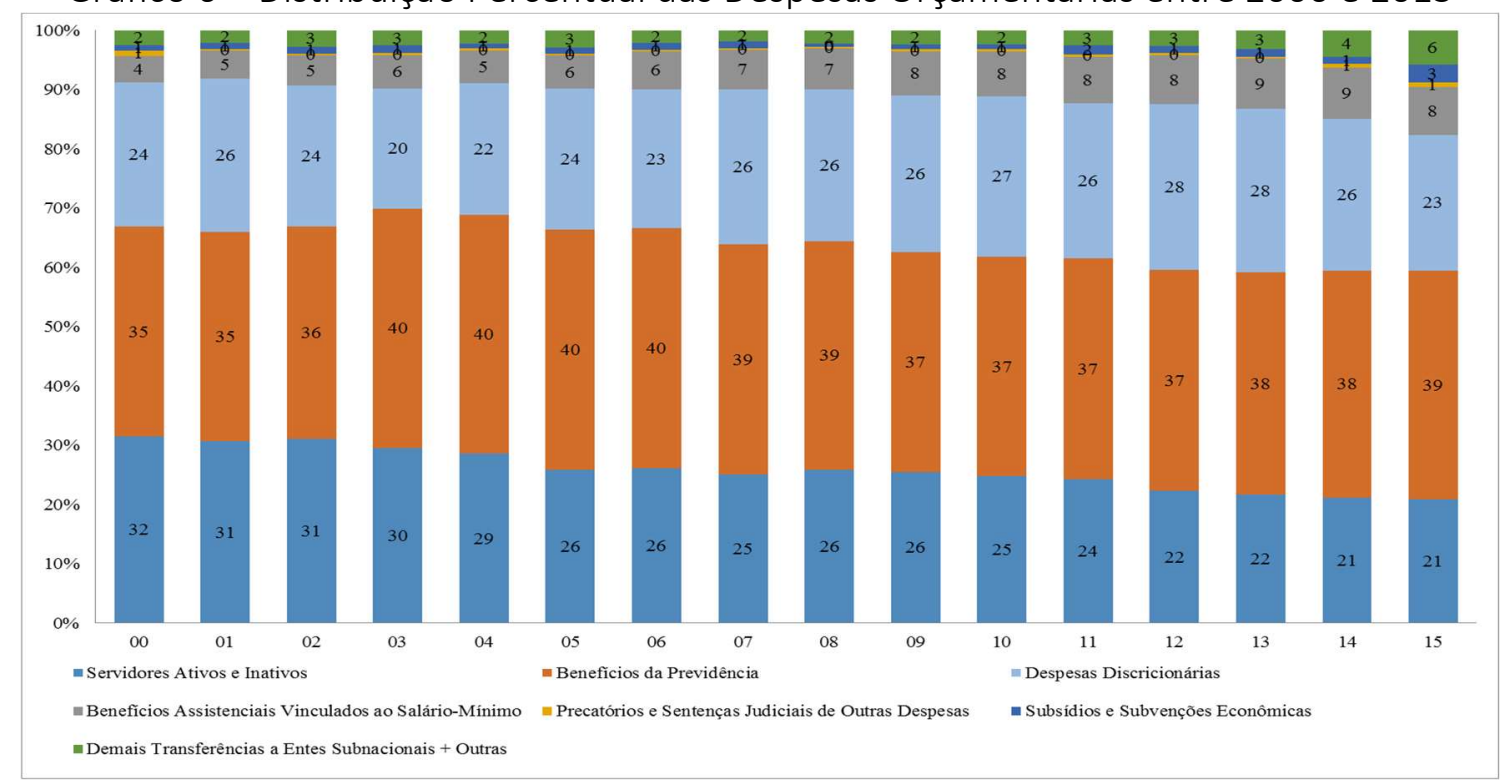

Fonte: Secretaria de Orçamento Federal (www.orcamentofederal.gov.br/)

Observa-se que três contas são responsáveis por praticamente $90 \%$ das despesas primárias do governo central: Benefícios da Previdência, Despesas com servidores ativos e inativos e Despesas discricionárias. É interessante notar que a participação das

\footnotetext{
${ }^{3}$ Segundo informações da Secretaria do Orçamento Federal, as despesas orçamentárias utilizadas para cálculo dos resultados primários podem ser divididas entre despesas obrigatórias e despesas discricionárias. As despesas obrigatórias são aquelas nas quais o gestor público não possui discricionariedade quanto à determinação do seu montante, bem como ao momento de sua realização, por determinação legal ou constitucional. Estas despesas possuem execução obrigatória e necessariamente têm prioridade em relação às demais despesas, tanto no momento de elaboração do orçamento, quanto na sua execução (SOF, 2016). Elas englobam as seguintes despesas: servidores ativos e inativos; benefícios da previdência e aqueles vinculados ao salário mínimo (abono salarial seguro desemprego, benefícios da Lei Orgânica de Assistência Social e Renda Mensal Vitalícia); outras transferências a entes subnacionais; Precatórios e Sentenças Judiciais; Subsídios e Subvenções Econômicas. Já as despesas discricionárias são aquelas que permitem ao gestor público flexibilidade quanto ao estabelecimento de seu montante, assim como quanto à oportunidade de sua execução, e são efetivamente as que concorrem para produção de bens e serviços públicos (SOF, 2016).
} 
p. 59 - Uma perspectiva crítica do novo regime fiscal para a dinâmica de curto e longo prazo da economia brasileira

despesas com servidores perdeu espaço entre os anos 2000 e 2015, apesar de ter apresentado um crescimento anual real médio de 4\%. Já as outras duas contas não variaram substancialmente sua participação ao longo desse período, mas cresceram, em média, 7\% ao ano em termos reais (7,2\% para Previdência e 6,6\% para despesas discricionárias). É válido destacar que essas três principais contas podem ser afetadas de modo diferenciado pela PEC 241/55.

As despesas discricionárias merecem uma análise mais detalhada porque é a rubrica do orçamento que afeta diretamente a oferta de serviços públicos à população. Dentre as três principais contas, as despesas discricionárias mantiveram sua participação praticamente estável durante 2000-2015, mas cresceram de forma instável durante esse período. Esta instabilidade pode ser reflexo da própria natureza dessa conta ao ser mais "maleável". Os dados sugerem indícios de que os gastos discricionários possuem características pró-cíclicas, aumentando (reduzindo) seus gastos em oferta de serviços públicos na fase ascendente (recessiva). Notamos que entre 2013 e 2015 a rubrica investimento caiu $18 \%$ em valores reais de 2000, ressaltando o caráter recessivo do ajuste fiscal implementado ainda pelo governo Dilma. O Gráfico 07 apresenta a distribuição dos gastos primários entre os ministérios. São ilustradas as rubricas do poder executivo por representarem, em todos os períodos, pelo menos $94,6 \%$ das despesas primárias, tal como o fornecimento de serviços públicos à população ${ }^{4}$. Podemos notar que pelo menos $55 \%$ das despesas primárias do poder executivo estão vinculadas à política social, sendo que a média nesse período foi de $61,1 \%$, com um coeficiente de variação pequeno (6,36\%, contra 18,7\% para Infraestrutura, 23,3\% para Produção e 10,44\% para Poderes de Estado e Administração).

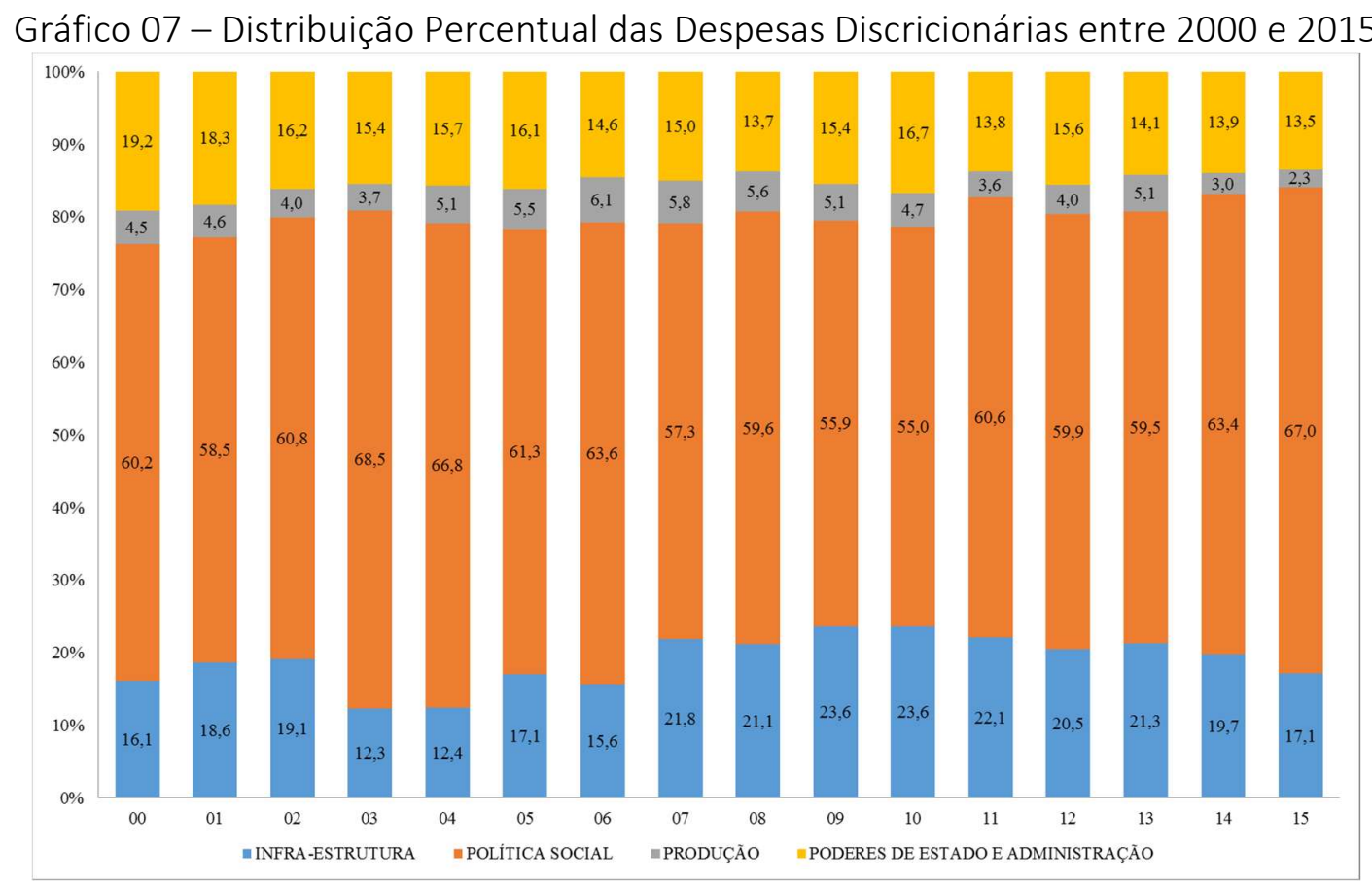

Fonte: Secretaria de Orçamento Federal (www.orcamentofederal.gov.br/)

\footnotetext{
${ }^{4}$ Os outros órgãos que realizam despesas discricionárias são referentes aos poderes judiciários e legislativos, incluindo o Ministério Público da União.
} 
Sobre a as despesas vinculadas à política social, observa-se que, no mínimo, 30\% das despesas discricionárias nesse período foi executada pelo Ministério da Saúde, chegando ao máximo de 46,4\%. Nesse período, destaca-se também o crescimento da importância do Ministério do Desenvolvimento Social e Combate à Fome, o qual aumentou sua participação de 2\% das despesas discricionárias em 2000 para 12,5\% em 2015. O Ministério da Educação também ganhou espaço, saindo de 10,3\% em 2000 para 15,2\% das despesas discricionárias em 2015, mas com maior oscilação (coeficiente de variação de 19,77\%, contra $13,6 \%$ da saúde), chegando a atingir um mínimo de 9,4\% das despesas discricionárias em 2004. Após 2003, estes foram os três principais ministérios relacionados aos gastos com Políticas Sociais do poder executivo. Porém, eles possuem dinâmicas específicas. Tanto os Ministérios da Saúde quanto da educação têm seus gastos mínimos vinculados à arrecadação (com peculiaridades) enquanto o ministério do desenvolvimento social e combate à fome pode ter sido uma escolha política. Com a PEC 241/55, o que se propõe é, a partir de 2018, retirar essa vinculação à receita e atrelar o gasto mínimo à inflação. Dada uma perspectiva de queda da inflação, essa retirada de vinculação afetaria, então, os dois principais ministérios responsáveis pelas despesas discricionárias voltadas à política social.

Quanto aos dispêndios voltados à infraestrutura, os principais ministérios eram, em 2015, o Ministério das Cidades e o dos Transportes. O Ministério das Cidades ganhou importância principalmente a partir de 2007, provavelmente com a decisão de sediar a Copa do Mundo e a Olimpíada. Já o Ministério do Transporte reduziu sua participação nas despesas discricionárias nesse período, mais especificamente entre 2010 e 2015, saindo de 8,7\% para 3,8\%. Complementar a isso, observa-se que o Ministério das Cidades cresceu de forma constante, em nível, suas despesas discricionárias nesse período 20072014, sofrendo uma queda em 2015. Já as despesas do Ministério dos Transportes vem reduzindo desde 2010, ocasionada provavelmente pela diminuição do ritmo das obras do PAC. Por fim, sobre as despesas discricionárias destinadas à produção, o principal ministério do período foi o do desenvolvimento agrário. Este a chegou a representar 2,6\% do total das despesas discricionárias em 2006, mas vem perdendo importância nos últimos anos, especialmente entre 2013 e 2015, chegando a apenas 0,8\% das despesas discricionárias totais. Novamente, tem-se um possível "efeito Copa do Mundo e Olimpíadas", onde, entre 2006 e 2010, a participação do Ministério do Turismo alcançou o maior valor (acima de 1\%). Já o MDIC teve uma pequena redução na sua participação, de $0,7 \%$ em 2000 para 0,4\% em 2015. Os Gráficos referentes à distribuição dos recursos destinados à política social e infraestrutura são apresentados abaixo. 
p. 61 - Uma perspectiva crítica do novo regime fiscal para a dinâmica de curto e longo prazo da economia brasileira

Gráfico 8 - Distribuição das despesas primárias com Políticas Sociais por Ministério.

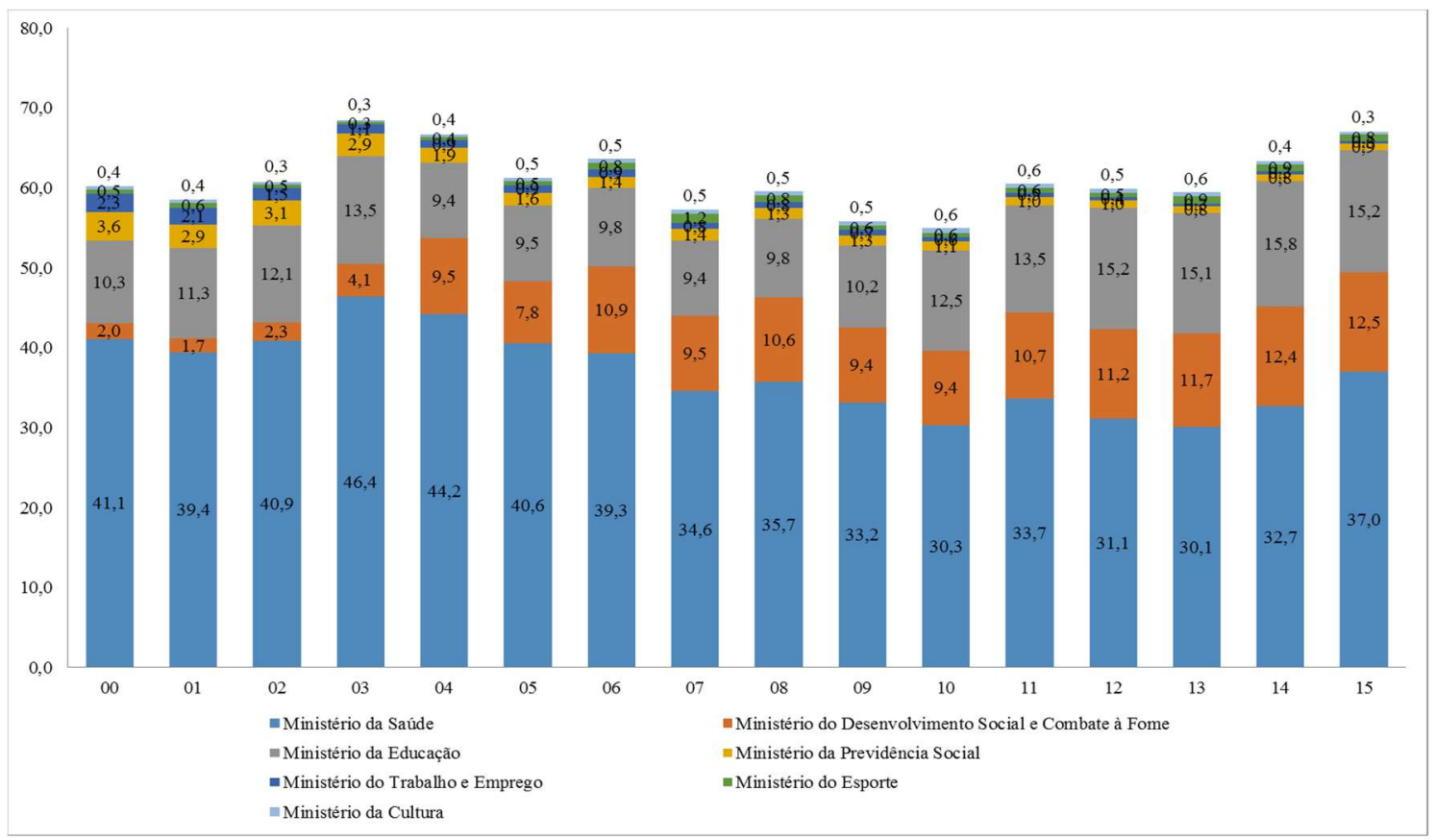

Fonte: Secretaria de Orçamento Federal (www.orcamentofederal.gov.br/)

Gráfico 9 - Distribuição das despesas primárias com infraestrutura por Ministério.

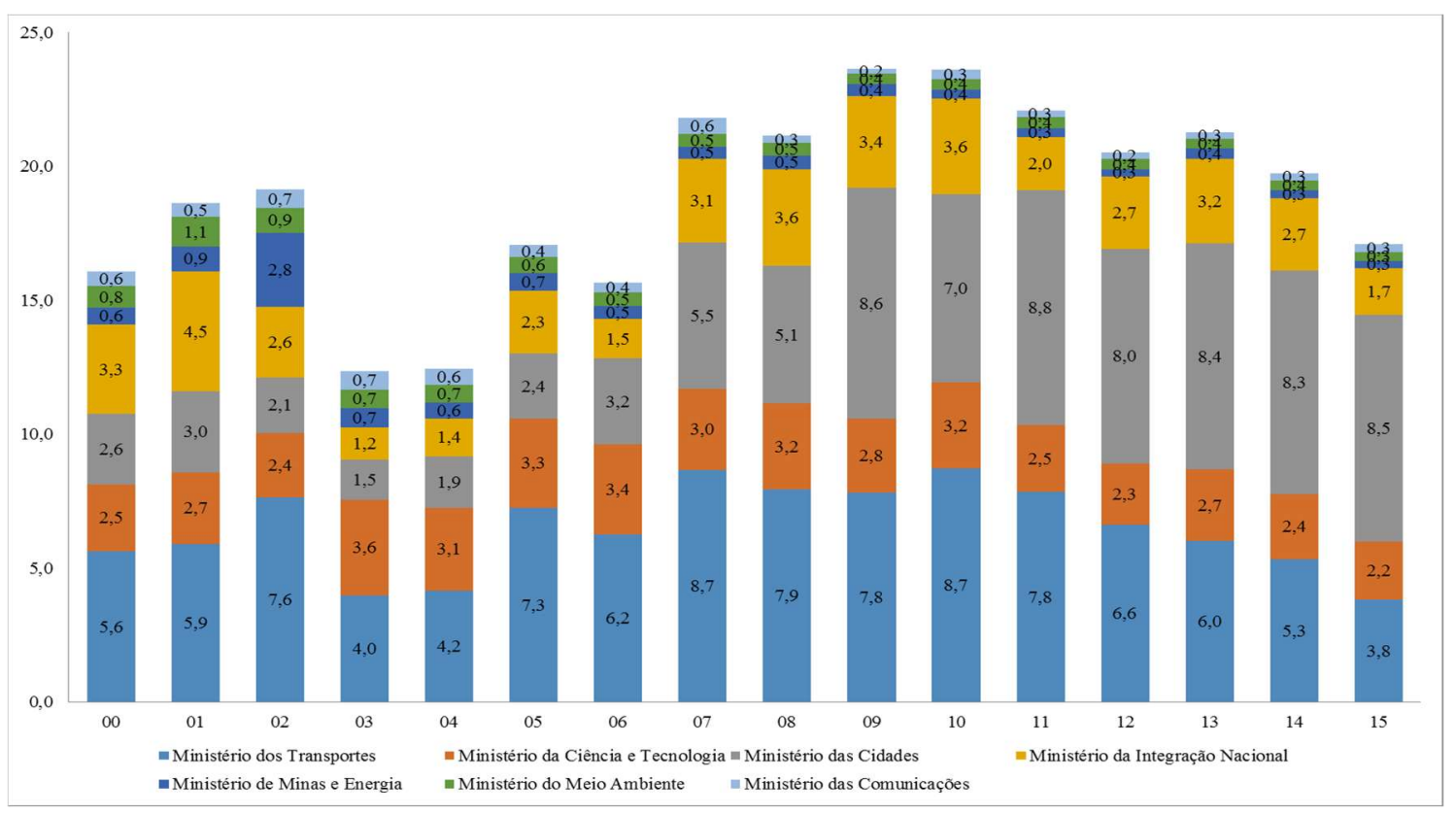

Fonte: Secretaria de Orçamento Federal (www.orcamentofederal.gov.br/)

As análises dos dados mostra que, em um contexto de teto real para os gastos públicos, a capacidade de realizar políticas públicas via despesas discricionárias fica comprometida, dado que algumas rubricas possuem dinâmicas específicas, como a previdência. Sugere-se que o congelamento real do orçamento implicará na absorção das despesas discricionárias pelos gastos obrigatórios que possuem uma dinâmica de 
crescimento específica. Os impactos da PEC sobre o orçamento da Saúde terão maiores efeitos no médio/longo prazo, posto que o novo regime fiscal antecipa para 2017 o percentual de 15\% da receita corrente líquida que seria aplicada apenas em 2020 pela regra anterior. Ou seja, isso implica em um ganho real próximo aos $\mathrm{R} \$ 10$ bilhões, sendo que a partir de 2018 os gastos passarão a ser corrigidos pela inflação. Segundo estimativas, as perdas de recursos orçamentários só passariam a ocorrer a partir de $2023^{5}$ (Viegas Andrade et al., 2017) ${ }^{6}$.

Em relação ao orçamento da educação, o novo regime fiscal afeta as despesas ao nível da União (responsável pela gestão de Universidades, Institutos e Escolas Federais, e pelo apoio financeiro via Fundo Nacional de Desenvolvimento da Educação- FNDE aos Estados e municípios). Segundo levantamento realizado pela Consultoria de Orçamento e Fiscalização Financeira da Câmara dos Deputados se a PEC 241/55 fosse aplicada desde 2011, os recursos destinados a educação teriam sidos reduzidos anualmente. Logo, evidencia-se que apenas em conjunturas econômicas recessivas é que se verificaria uma melhora na aplicação dos recursos.

Por outro lado, a UNESCO (2010) indica que o gasto doméstico bruto em P\&D é realizado majoritariamente pelo setor público (55\%), sendo que $90 \%$ dos artigos científicos são gerados em Universidades Federais e aproximadamente $75 \%$ dos cientistas são acadêmicos. Não obstante, as pesquisas realizadas no âmbito empresarial são amplamente amparadas por políticas públicas orientadas pelo extinto Ministério da Ciência, Tecnologia e Inovação. Menezes Filho (2016) aponta que a vinculação de gastos das pastas da saúde e educação não deveria ocorrer por uma série de motivos, como:

a) Os gastos em educação e saúde não foram os principais responsáveis pela crise fiscal, sendo que os recursos aplicados na saúde estão estáveis em proporção ao PIB há anos, e os aplicados à educação aumentaram acima da vinculação nos últimos anos devido a programas equivocados, que devem ser reduzidos;

b) Os gastos nestas áreas beneficiam grande parcela da população e a que necessita de investimentos para a promoção da redução da desigualdade e aumento da produtividade no país;

c) O sistema de vinculação funciona bem, posto que $18 \%$ das receitas do governo federal e $25 \%$ dos Estados e municípios são direcionados à educação, e neste sentido, se a receita aumenta, os investimentos também;

d) Com a PEC, se a inflação se estabilizar e o PIB voltar a crescer, os gastos com saúde e educação em relação ao PIB reduzirão, posto que seus benefícios são dispersos e os usuários desses serviços tem poder de barganha reduzido no congresso.

Outro aspecto que reforça o teor do conflito distributivo presente nas despesas discricionárias com a PEC 241/55 é a remarcação de preços do setor privado (que busca ganhos reais), de quem o Estado adquire bens e serviços. Segundo Bittes Terra (2016),

\footnotetext{
${ }^{5}$ Ver Mendes (2016).

${ }^{6}$ Ressalta-se que o aumento dos preços vinculados à área da saúde são maiores e possuem dinâmica diferente dos outros preços da economia em decorrência do aumento e do envelhecimento populacional, e por ser um setor oligopolizado e dependente de importações de máquinas e equipamentos, e, portanto, vulnerável a oscilações cambiais. Neste sentido, a diferença entre o IPCA e os preços da área da Saúde poderá implicar em redução real do montante orçado para a Saúde, mesmo em períodos de recessão.
} 
p. 63 - Uma perspectiva crítica do novo regime fiscal para a dinâmica de curto e longo prazo da economia brasileira

assumindo a valorização do salário mínimo como uma proxy do custo a ser enfrentado pelo setor público ao adquirir bens e serviços do setor privado e assumindo que a lei da valorização real do salário mínimo permaneça pelos anos de vigência do novo regime fiscal e que o salário cresça em média 6,5\% ao ano, 4,5\% referente à inflação e $2 \%$ ao PIB, tem-se um quadro em que o crescimento acumulado dos custos a serem pagos ao setor privado seria de $55,4 \%$, ante uma possibilidade de expansão de $36 \%$ dos gastos públicos entre 2020 e 2026, ano de revisão da PEC. Esse valores passariam para 191\% e 111\%, respectivamente, entre 2020 e 2036.

\subsection{A Reafirmação da Condição de Subdesenvolvimento}

Segundo a abordagem teórica neo-schumpeteriana evolucionária, os países não tem acesso livre às inovações, ou ainda, a tecnologia não é um bem público (Fagerberg,1995). O crescimento das economias aquém da fronteira tecnológica está relacionado, portanto, aos esforços nacionais de assimilação da tecnologia dos países centrais e do desenvolvimento tecnológico genuinamente nacional.

Não obstante, o processo de catching up baseado na inovação tecnológica não é um procedimento automático. A assimilação da fronteira tecnológica e o desenvolvimento de tecnologia nacional não respeitam uma lógica mecânica e trivial. Para Fagerberg (1994), isto requer a construção de um aparato institucional adequado, o que se pode chamar de um Sistema Nacional de Inovação (SNI). Albuquerque (1996) ressalta que o SNI é o resultado de ações planejadas ou não, que considerem a complexidade das economias capitalistas na promoção do desenvolvimento tecnológico nacional.

Esses arranjos institucionais envolvem as firmas, redes de interação entre empresas, agências governamentais, universidades, institutos de pesquisas, laboratórios de empresas, atividades de cientistas e engenheiros. Arranjos institucionais que se articulam com o sistema educacional, com o setor industrial e empresarial, e também com as instituições financeiras, completando o circuito dos agentes que são responsáveis pela geração, implementação e difusão das inovações (ALBUQUERQUE, 1996, pg.02).

Assim, a constituição do SNI depende de atividades fortemente relacionadas às atividades do Estado, como agências governamentais de pesquisa e de educação superior, bem como da disponibilidade de financiamentos das atividades inovativas. A forte participação do Estado no desenvolvimento tecnológico, no caso brasileiro, verificase quando se observa, por exemplo, que a infraestrutura de pesquisa nacional é formada 
por laboratórios de universidades ${ }^{7}$, na imensa maioria de instituições públicas ${ }^{8}$, e que o financiamento destas atividades é feito basicamente por agências governamentais como o CNPQ, fundações de amparo à pesquisa, PETROBRAS e FINEP (De Negri e Squeff, 2016). As empresas privadas financiam apenas $7 \%$ das receitas destinadas à atividade de infraestrutura em pesquisas de inovação (De Negri e Squeff, 2016).

Em consonância ao exposto, Furtado (1978) mostra que a condição de subdesenvolvimento econômico é peculiar ao próprio desenvolvimento como história do capitalismo moderno. Nas palavras do autor "desenvolvimento e subdesenvolvimento devem ser considerados como dois aspectos de um mesmo processo histórico, ligado à criação e à forma de difusão da tecnologia moderna (Furtado, 1978. p. 8-9)". Para Furtado (1978), o subdesenvolvimento surge como uma construção histórica do capitalismo contemporâneo, não sendo uma etapa do processo de desenvolvimento (no sentido de Rostow, 1956), mas uma condição que tende a se autoperpetuar. Somente a ação estatal, especialmente como um vetor indutor do progresso tecnológico e da acumulação de capital é capaz de gerar as condições necessárias para a superação dessa condição de atraso (Missio et all. 2015).

Logo, argumenta-se que com a PEC 55/241 haverá uma redução dos gastos públicos em saúde e na educação superior, nos recursos destinados à pesquisa em inovação tecnológica e em infraestrutura, o que tende a ter impactos negativos na trajetória de longo prazo da economia brasileira, reafirmando sua da condição de subdesenvolvimento.

\section{CURTO PRAZO: A CONSISTÊNCIA DA PEC 241/55}

\subsection{A PEC 241/55 e a Inércia Inflacionária}

A PEC 241/55 reforça a indexação da economia brasileira ao reajustar os gastos primários conforme a taxa de inflação pretérita. O caráter inercial surge das expectativas inflacionárias dos agentes vis a vis à proteção de suas rendas relativas. O anúncio governamental de um aumento do gasto nominal conforme a inflação passada induzirá os agentes à percepção de que as respectivas rendas relativas (preços) sofreram uma perda real de tal magnitude. Para evitar transferência de renda real, os agentes incorporam a mesma regra de reajuste aos seus preços via expectativas. Nesse processo, destacam-se os setores oligopolistas que, além de incorporar a inflação passada, podem tentar a aumentar os preços conforme uma expectativa de inflação crescente, o que geraria uma espiral inflacionária.

\footnotetext{
7 Um dos poucos consensos entre as diferentes escolas de pensamento econômico refere-se ao papel fundamental do investimento, do capital humano e do progresso técnico para o crescimento econômico. Pois bem, a PEC não traz nenhum mecanismo que melhora significativamente nenhuma das variáveis referidas, justamente porque o governo não tem uma agenda de crescimento. E, mais, a EMI (00083/2016) fala em melhoria da eficiência, tanto em relação aos gastos como às instituições fiscais, só que não explicita nenhum novo mecanismo (e nem reformas a serem realizadas). É, portanto, portadora de um discurso vago e ideológico acerca de possíveis (e aparentemente únicos e suficientes) "ganhos" advindo de um problema de otimização com restrição.

${ }^{8}$ Para ver estas informações, o leitor deve ter acesso ao apêndice B de De Negri e Squeff (2016), disponível em www.ipea.gov.br/agencia/images/stories/PDFs/livros/livros/livro_sistemas_setoriais.pdf.
} 
p. 65 - Uma perspectiva crítica do novo regime fiscal para a dinâmica de curto e longo prazo da economia brasileira

A inércia inflacionária, ou a rigidez nominal, altera as implicações relacionadas ao trade-off da curva de Phillips. Mesmo que a economia possua uma dinâmica recessiva em termos de demanda agregada, a inflação não cederá por que os agentes incorporarão a inflação pretérita em suas expectativas inflacionárias com vistas a se proteger de uma possível transferência real de renda. Ou seja, a variação do nível de preços atual em partes é determinada pelos preços pretéritos, o que na prática significa rigidez nominal. Assim, a inflação reage menos ao desemprego e/ou ao produto.

Em síntese, a incorporação do reajuste de preços via expectativas dos agentes implica em um maior grau de indexação da economia e, como a dinâmica de preços passa a depender em menor do ajuste entre a oferta e a demanda agregada tem-se a perda de eficiência da política monetária para controlar o nível de preços. Como consequência, a economia brasileira exigirá taxas de juros maiores para reduzir a taxa de inflação, o que implica em um elevado custo de emprego e renda. É possível, portanto, que a economia fique presa num quadro de inflação alta, juros elevados e crescimento baixo ${ }^{9}$. Essa situação tende a agravar também o quadro fiscal, uma vez que a elevação da taxa de juros piora as contas nominais dado que: i) a elevação da taxa de juros tende a desacelerar a economia e, com isso, a arrecadação tributária diminui; e, ii) a elevação da SELIC indica maiores pagamentos de juros, o que por sua vez pressiona a situação primária das contas públicas. Nesse caso, o Estado terá que reduzir os gastos primários para obter equilíbrio nas contas nominais.

\subsection{A PEC $241 / 55$ enquanto proposta de crescimento}

O novo regime fiscal foi proposto em um contexto de grave crise das contas públicas, como principal instrumento de reversão da tendência deficitária e consequente aumento da dívida pública. Há, no entanto, uma série de críticas à forma como foi apresentado e conduzido todo esse processo. A começar pelo fato de que o "novo" regime fiscal apenas traz modificações no lado da despesa e, portanto, não está claro como isso é "condição necessária para corrigir o desequilíbrio das contas públicas" (EMI 00083/2016). Se, por um lado, algum controle dos gastos ajuda a mitigar o problema fiscal ${ }^{10}$, por outro, deve-se considerar que a receita e a despesa do Estado não são algo totalmente independente (e, portanto, não vale a parábola do orçamento familiar). Ademais, há graus de liberdade bastante claros no debate de como o Estado poderia melhorar a arrecadação de receitas tributando, por exemplo, patrimônio e renda (sem afetar o consumidor e o produtor) ou revendo a política de isenções e subsídios (estimadas em mais de R\$ 200 bilhões por ano). Em outras palavras, a PEC 241/55 representa uma política de "austeridade seletiva"11.

\footnotetext{
9 Se considerarmos, por exemplo, a literatura recente sobre a curva de Phillips (ver Razin, 2004), que incorpora um terceiro elemento que é o produto potencial, e admitirmos que o produto potencial dependa da acumulação de capital e este, por sua vez, da taxa de juros, fica evidente como um aumento da taxa de juros, ao reduzir o produto potencial, tende a aumentar a inflação.

${ }^{10}$ Especialmente controlando a taxa de crescimento das despesas (não necessariamente o nível).

${ }^{11}$ É altamente criticável o fato de que as isenções fiscais realizadas recentemente no Brasil, em geral, terem sido feitas sem as exigências de contrapartidas (em termos de investimento, emprego, etc) por parte das
} 
Seguindo o raciocínio, é evidente que a PEC 241/55 carrega a ideologia do there is no alternative. Na EMI (00083/2016) argumenta-se que por conta do desarranjo fiscal elevou-se o prêmio de risco da economia brasileira que, seguido da perda de confiança dos agentes e da elevação dos juros, acabaram deprimindo o investimento e, consequentemente, o desempenho em termos do crescimento. Nesse raciocínio, sustenta-se que ações para dar sustentabilidade às despesas públicas são o único caminho para a recuperação da confiança, a ser traduzida na volta do crescimento.

Ora, se é possível considerar que o desajuste fiscal tem impacto sobre o "prêmio de risco", é necessário levar em consideração que eventos não recorrentes também o afetam, como o cenário internacional (crise internacional, condições do mercado financeiro internacional) ou mesmo as oscilações da taxa de câmbio ${ }^{12}$. Ademais, deve-se considerar que o "prêmio de risco" exigido pelos compradores de títulos públicos, o qual reflete as suas expectativas quanto a possibilidade de um default sobre os papéis do governo, depende positivamente do déficit fiscal operacional que, por sua vez, depende da taxa real de juros que incide sobre o estoque de endividamento público. Portanto, o conservadorismo do Banco Central, ou mesmo uma política de ajuste inadequada, que resulte na elevação (manutenção em elevados níveis) desnecessária da taxa de juros também altera o prêmio de risco ${ }^{13}$. Neste ponto, cumpre fazer uma ressalva: uma política alternativa não significa reduzir os juros "na marra", como sendo a solução final. Mas, sim, admitir que frente a uma das piores recessões da história da economia brasileira é possível adotar uma política monetária menos restritiva (em relação aos juros) em um cenário em que a taxa de inflação esperada converge para a meta. É admitir, também, a possibilidade da utilização de outros instrumentos no controle da inflação, como os depósitos compulsórios e os requerimentos de capital próprio. E, por fim, é implementar uma ampla reforma das condições estruturais que mantém a taxa de juros elevada no Brasil, a começar pela quebra da indexação de preços e contratos.

Ainda existe um longo caminho a ser percorrido (e explicado) entre uma redução do risco-país e o aumento da taxa de investimento. Essa relação não é direta e unidirecional. Pelo contrário, boa parte dos economistas acreditam que o empresário toma a decisão de investir com base na comparação entre a taxa de retorno esperada do investimento (eficiência marginal do capital, doravante Emgk) e o custo de oportunidade do capital a ser investido, que é dado pela taxa para obtenção de fundos ou de aplicação de recursos no mercado financeiro (taxa de juros). A Emgk depende das expectativas em relação ao retorno desse capital. As expectativas, por sua vez, dependem do otimismo dos empresários e do grau de confiança nesse otimismo. Observe que em qualquer decisão de investimento o empresário se vê obrigado a antever a evolução futura e, portanto, incerta do mercado para o produto específico a ser gerado pelo investimento.

empresas beneficiárias. No entanto, a PEC não só mantem essas isenções, como se quer menciona a possibilidade da inclusão dessas exigências (mesmo a ser regulamentadas posteriormente).

${ }^{12}$ A hipótese Bresser-Nakano admite a endogeneidade do prêmio de risco, sendo este positivamente relacionado com a taxa de juros doméstica (e com sua trajetória temporal) e com a taxa nominal de câmbio. 13 Ademais, segundo Bresser e Nakano (2002), o mercado financeiro internacional pode acabar interpretando uma redução da taxa de juros como, na verdade, uma redução do prêmio de risco, uma vez que uma taxa de juros muito elevada pode sinalizar uma alta probabilidade de default devido aos problemas de seleção adversa e risco moral por parte dos tomadores de empréstimos. 
p. 67 - Uma perspectiva crítica do novo regime fiscal para a dinâmica de curto e longo prazo da economia brasileira

A importância das expectativas está relacionada à existência de incerteza, decorrente da diferença de tempo entre a tomada de decisão e sua realização (temporalidade).

Acontece que num cenário de crise, os empresários estão pessimistas quanto ao volume de vendas que vão realizar no futuro e, portanto, num cenário em que eles projetam uma redução (ou estagnação) do volume de vendas (da demanda), eles vão adiar os projetos de investimento. Mesmo a redução da taxa de juros pode não estimular os investimentos, caso o otimismo (refletido na Emgk) seja baixo. Neste ponto, ao contrário do que foi afirmado na EMI (00083/2016), a PEC 241/55 pode levar a redução do investimento. Isso porque o mecanismo de ajuste fiscal, em termos práticos, reduz a possibilidade de o Estado fazer políticas de estimulo da demanda agregada e, portanto, sinalizar para os empresários que no futuro é possível que eles se defrontem com um aumento da demanda por seus produtos. Em outras palavras, o Estado perde a capacidade de aquecer a economia e estimular a iniciativa privada que, por sua vez, pode ficar em estado de inação por um longo período ${ }^{14}$.

Por fim, cumpre ressaltar que a recuperação da confiança pode não se traduzir em crescimento como anunciado na EMI (00083/2016). O crescimento econômico, como descrito anteriormente, depende do volume de investimentos e de demais políticas de demanda agregada, bem como de variáveis que afetam o lado da oferta, como a formação bruta de capital, os ganhos exógenos de produtividade, etc. Em outras palavras, a PEC 241/55 tem muito pouco a ver com uma agenda de crescimento e muito menos com as prioridades do desenvolvimento brasileiro (tais como redução da desigualdade social, aumento do emprego e renda, resolução do o sistema tributário que é regressivo e complexo, redução da burocracia, etc). Em suma, o governo não tem uma política econômica bem definida para retomar o crescimento da economia e insiste em pautas que, ainda que demandem uma discussão ampla e aprofundada, não são adequadas nesse momento de instabilidade política, social e econômica.

\section{CONSIDERAÇÕES FINAIS}

A dinâmica da economia brasileira, concomitante à situação política, sofreu forte depreciação a partir de 2014. No triênio 2014-2016, a economia registrou as piores taxas de crescimento das últimas décadas. As perspectivas para os próximos anos também não são nada animadoras. Segundo a previsão do Banco Central a economia brasileira vai crescer 0,50\% em 2017 (Boletim Focus, 2016). O quadro fiscal deteriorou-se significativamente nesse período. A queda da arrecadação tributária, como consequência da recessão econômica, somado a problemas estruturais (como a presença de uma estrutura produtiva atrasada e de baixa complexidade, ou a alocação da mão de obra em setores com baixa produtividade) e a opções de políticas econômicas (desonerações tributárias, subsídios fiscais e parafiscais etc) levaram ao aparecimento de um déficit significativo.

A solução encontrada pelo governo foi estabelecer um novo regime fiscal que congela os gastos públicos para os próximos 10 anos. A proposta levada adiante pelo

\footnotetext{
14 Em especial, no caso atual em que as empresas estão endividadas, com capacidade ociosa e não conseguem vender.
} 
governo é questionável. Como buscamos demonstrar, a PEC 241/55 não só limita as margens de política fiscal, mas também requer a aprovação de outras reformas para ter alguma chance de sucesso. Ou seja, seus resultados estão condicionados a elaboração de reformas como a da previdência, do regime de trabalho dos servidores públicos, dos benefícios reajustados pelo salário mínimo, entre outros. Neste ponto, há duas discussões a serem feitas: a primeira refere-se ao fato de que, na ausência de tais reformas (ou na demora em sua aprovação):

a) No longo prazo: fica evidente que haverá redução dos gastos discricionários, o que implica na redução da oferta de serviços públicos; em outras palavras, a somatória do congelamento real com uma dinâmica específica de algumas rubricas do orçamento implica necessariamente em redução da rubrica gastos discricionários. Por isso, no longo prazo, pode-se argumentar que a redução dos gastos em educação superior e saúde (capital humano), em atividades científicas relacionadas à $P \& D$ e infraestrutura reduzem as possibilidades de um catching up conforme o escopo teórico neo-schumpeteriano. O que do ponto de vista de Furtado (1978) implica na reafirmação da condição de subdesenvolvimento.

b) No curto prazo: a limitação dos gastos discricionários e em investimentos implica na redução da capacidade do governo de estimular a demanda agregada nos períodos de crise. Mais que isso, pode implicar em um perverso mecanismo de criação de inércia inflacionária (ou rigidez nominal) o que pode implicar na redução da eficácia da política monetária no controle de preços via redução da demanda agregada. Daí que o controle inflacionário exige taxas de juros mais elevados, criando um efeito deletério no quadro fiscal à medida que: i- reduz a arrecadação fiscal em detrimento da redução da atividade econômica, e iiaumenta o pagamento de juros, o que indica um esforço no sentido de transferir recursos do orçamento primário para obter-se equilíbrio nas contas nominais, isto é, para pagar juros sem ocorrer em déficits. Por outro lado, argumentou-se que o Novo Regime Fiscal não garante o crescimento econômico, sobretudo nas fases de depressão do ciclo econômico à medida que o Estado perde autonomia da política fiscal.

\section{REFERÊNCIAS BIBLIOGRÁFICAS}

ALBUQUERQUE, E. DA M. E. Sistema Nacional de Inovação no Brasil: Uma análise introdutória a partir de dados disponíveis sobre a ciência e tecnologia. Revista de Economia Política, v. 16, n. 3, p. 56-72, 1996.

Austeridade e retrocesso - finanças públicas e política fiscal no Brasil. São Paulo: Fórum, 21; Fundação Friedrich Ebert Stiftung (FES); GT de Macro da Sociedade Brasileira de Economia Política (SEP); e Plataforma Política Social, setembro de 2016.

EMI no00083/2016. Ministério da Fazenda. Ministério do Planejamento, Desenvolvimento e Gestão. Brasília, 15 de Julho de 2016.

BRASIL. Proposta de Emenda Constitucional no 55, de 26 de outubro de 2016. Altera o Ato das Disposições Constitucionais Transitórias, para instituir o Novo Regime Fiscal. Brasília 
p. 69 - Uma perspectiva crítica do novo regime fiscal para a dinâmica de curto e longo prazo da economia brasileira

BRESSER-PEREIRA, L.C. e Y. NAKANO (2002) "Uma Estratégia de desenvolvimento com Estabilidade". Revista de Economia Política, 22 (3), julho 2002: 146-177. Disponível em: http://www.rep.org.br/pdf/87-10.pdf

BITTES TERRA, F. "Há tratamento além da camisa de força da PEC 241?" Jornal Valor Econômico. 20/10/2016.

DE NEGRI, F. SQUEFF, F. H. S. O Mapeamento da Infraestrutura Científica e Tecnológica no Brasil. In: Sistemas Setoriais de Inovação e Infraestrutura de Pesquisa no Brasil. IPEA, 2016.

FAGERBERG, J. Evolutionary Economics III Catching up and falling behind in economic development : Convergence or divergence ? The impact of technology on " why growth rates differ "*. Evolutionary Economics, p. 19-22, 1995.

FURTADO, C. A Hegemonia dos Estados Unidos e o Subdesenvolvimento da América Latina. 1ํ. ed. Rio de Janeiro: Civilização Brasileira, 1978.

MENEZES FILHO, N. "Governo deve desvincular gastos obrigatórios em educação e saúde? NÃO". Jornal Folha de São Paulo. 11/06/2016 Disponível em: http://www1.folha.uol.com.br/opiniao/2016/06/1780648-governo-deve-desvinculargastos-obrigatorios-em-educacao-e-saude-nao.shtml

MENDES, M. J. A PEC 241 e a Saúde. Portal Monitor da Saúde. Novembro de 2016. Disponível em: http:monitordesaude.blogspot.com.br/

MENDLOVITZ, M. Análise dos Efeitos da PEC n-241 sobre a Manutenção e Desenvolvimento do Ensino. Estudo Técnico. Câmara dos Deputados. Consultoria de Orçamento e Fiscalização Financeira. 11/2016

MISSIO, F. J.; JAYME JR., F. G.; OREIRO, J. L. (2015). The structuralist tradition in economics: methodological and macroeconomics aspects. Revista de Economia Política (Impresso), v. 34, p. 247-266.

PIRES, M. C. C. (2016). Política econômica e estabilização: uma breve análise da recessão brasileira. Brazilian Keynesian Review, 2 (2), p.247-251.

RAZIN, A. (2004). Aggregate supply and potential output, Working Papers - Hong Kong Institute for Monetary Research, n. 142004.

ROSSI, P.; MELLO, G. (2016). Componentes Macroeconômicos e Estruturais da Crise Brasileira: o Subdesenvolvimento. Brazilian Keynesian Review, 2 (2), p.252-263.

ROSTOW, W. W. The Stages of Economic Growth. The Economic History Review, v. 12, n. 1, p. 1-16, 1959.

UNESCO. Relatório da UNESCO sobre Ciência 2010. O Atual status da ciência em torno do Mundo. Resumo Executivo. 2010.

VIEGAS ANDRADE, M. NORONHA, K. TURRA, C. M. A PEC dos gastos e o SUS. Revista Conjuntura Econômica. Volume 71 nำ1. Janeiro de 2017. 